\title{
Possibilidade de desenvolvimento do Pensamento Computacional por meio do CODE.ORG: aplicado ao Ensino Fundamental (anos iniciais)
}

\author{
Myllena Silva de Freitas Morais, Pauleany Simões Morais \\ Campus Natal-Zona Norte - Instituto Federal do Rio Grande do Norte (IFRN) Natal - \\ Rio Grande do Norte - Brasil \\ myllenasfreitas@gmail.com, pauleanymorais@gmail.com
}

\begin{abstract}
This paper analyzes the developement of computational thinking in elementary education by the use of software that provide the study of the concepts of programming logic. The research seeks observe the contributions of computational thinking in the process of knowledge construction and learning in elementary school. It was an action research through practical activities that systematized the individual and coletive learning of the students about the concepts of programming logic. The results show that's possible the inclusion of the computational thinking in the student's school routine in a way that arouses student's interest, stimulating to an constructive technologic learning.
\end{abstract}

\begin{abstract}
Resumo. Este trabalho analisa o desenvolvimento do Pensamento Computacional no Ensino Fundamental Anos Iniciais por meio de softwares que proporcionam o estudo dos conceitos da lógica de programação. Buscouse na pesquisa observar as contribuições do Pensamento Computacional no processo de construção do conhecimento e aprendizagem na Educação Básica, sendo realizado uma pesquisa-ação, mediante atividades práticas que sistematizaram o aprendizado individual e coletivo dos alunos sobre os conceitos da lógica de programação. Os resultados obtidos mostram que é possivel incluir o Pensamento Computacional no cotidiano escolar de maneira que desperte o interesse dos alunos, estimulado a uma aprendizagem tecnológica construtiva.
\end{abstract}

\section{Introdução}

A sociedade atual está visualizando um novo processo no uso dos conhecimentos da área de Computação, passando por diversas atividades humanas. Já não é possível separar, nem considerar uma sociedade sem computadores e apropriação de tecnologias (FRANÇA, 2014). Segundo Wing (2016), todas as áreas de conhecimento estão interligadas a algum tipo de computador por meio de um pensamento interdisciplinar.

Os conceitos do Pensamento Computacional se baseiam em fundamentos da Computação envolvendo a resolução de problemas, desenvolvendo a capacidade de projetar sistemas e a compreensão do comportamento humano (WING, 2006) e vem sendo discutido cada vez mais no âmbito da Educação Básica.

Sabe-se que é um desafio disseminar o pensamento computacional sugerindo ferramentas que possam apoiar a aprendizagem de conceitos de lógica de programação para crianças e jovens, porém estudos como esse possibilita a disseminação dessa proposta, mostrando como são significativos os resultados desses conceitos introduzidos na Educação Básica. Muitos estudiosos defendem que a Ciência da Computação por meio dos computadores, ajuda a sociedade não apenas a aprender, mas possibilita uma 
VIII Congresso Brasileiro de Informática na Educação (CBIE 2019)

Anais do XXV Workshop de Informática na Escola (WIE 2019)

nova forma de aprendizagem (PAPERT, 1980). Trata-se também de formar os indivíduos para "aprender a aprender", de modo a serem capazes de lidar positivamente com a contínua e acelerada transformação da base tecnológica (MCT, 2000, p. 45).

Portanto, este estudo apresenta as contribuições do Pensamento Computacional no desenvolvimento do processo de ensino aprendizagem de alunos do Ensino Fundamental, utilizando conceitos da lógica de programação por meio do Lightbot e o Scratch, ferramentas disponíveis na plataforma do CODE.ORG.

\section{Metodologia}

O trabalho aqui apresentado utilizou procedimentos metodológicos em que o uso da tecnologia serviu de auxílio na construção do conhecimento, sendo promovido o envolvimento dos indivíduos no planejamento e na elaboração de um projeto, com um significado e os levando a reflexão sobre o processo de aprendizagem vivenciado (VALENTE, 1998).

Foi realizado uma pesquisa-ação, optando pela pesquisa qualitativa, de caráter exploratório. Vergara (2009) define que a pesquisa-ação é realizada em áreas na qual há pouco conhecimento acumulado e sistematizado. Por sua natureza de sondagem, não comporta hipóteses que, todavia, poderão surgir durante ou ao final da pesquisa. As experiências foram vivenciadas pelos alunos do Ensino Fundamental - Anos Iniciais do Colégio Imaculada Conceição de ensino particular, localizado na cidade de Campina Grande-PB, em que se aplicou os conceitos do Pensamento Computacional por meio dos atividades do CODE.ORG.

Os sujeitos envolvidos na pesquisa foram organizados em amostras de alunos do $2^{\circ}$ ao $5^{\circ}$ Ano (entre 7 e 10 anos) do Ensino Fundamental - Anos iniciais, totalizando de 150 alunos do turno manhã e tarde. As aulas com os jogos do CODE foram organizadas e ministradas em $01 \mathrm{~h}$ por semana, no período de agosto a dezembro do ano de 2018 . O colégio disponibiliza de laboratórios contendo 20 computadores e 10 tablets, todos com acesso à internet. As ferramentas de estudos selecionadas na pesquisa foram o Lightbot e o Scratch disponíveis na plataforma do CODE.ORG, usando como critério de seleção a ludicidade e a facilidade de compressão de uso, como também a quantidade de possíveis vias de aprendizagens da lógica de programação. Após coleta de dados realizou-se uma análise do conteúdo a partir dos fundamentos teóricos, estudos e dados colhidos na pesquisa.

\section{Avaliação da atividade realizada}

Diante de uma análise dentre os jogos disponibilizados no Code.org por meio da página da "Hora do código", realizou-se a primeira etapa onde foram selecionados o Lightbot e o Scratch que poderiam, a partir da experiência de sua execução, desenvolver junto aos alunos a aprendizagem de conceitos básicos da Ciência da Computação, diretamente ligados ao Pensamento Computacional e a linguagem de programação.

O Lightbot é um jogo de codificação, com seu layout baseado em um jogo de quebra-cabeça. O objetivo principal é programar um robô por meio do uso de ícones. Com suas codificações, os alunos podem definir qual o percurso deve ser realizado pelo robô enviando assim comandos ao computador, que mediante a sequência lógica executa cada instrução programada. Com o Lightbot o aluno pode aprender sequenciamento, sobrecarga, procedimentos, loops recursivos e condicionais. 
VIII Congresso Brasileiro de Informática na Educação (CBIE 2019)

Anais do XXV Workshop de Informática na Escola (WIE 2019)

A Linguagem de programação Scratch $^{1}$ é um software educacional de programação que utiliza uma linguagem visual em blocos, que se conectam e formam programas. Criada em 2007 pelo Media Lab do MIT (Instituto de Tecnologias de Massachusetts), é ideal para quem está começando a aprender sobre programação e projetado especialmente para a idade de 8 a 16 anos. O Scratch possibilita que os usuários possam criar suas próprias animações, estórias e jogos, dessa maneira é possível pensar de forma criativa e melhorar a capacidade de raciocínio. A programação é realizada utilizando blocos de comandos que serão montados em forma de quebracabeça.

$\mathrm{Na}$ segunda etapa do projeto os alunos foram divididos em grupos que utilizando tablets da escola com acesso à internet, exploraram o Lightbot. Por ter sua estrutura em forma de fases os grupos foram instruídos a trabalhar a fragmentação do problema para se chegar à sua solução, como sugere os pilares do Pensamento Computacional, dessa forma cada aluno ia resolvendo uma fase ou uma parte do problema, garantindo a participação de todos e diminuindo o tempo de resolução. Na experiência direta com uma linguagem de programação, os alunos estudaram o Scratch, agora realizando os estudos em computadores e em dupla.

Durante as atividades, os alunos foram observados e questionados sobre a sua experiência com a programação. Ao final de cada etapa apresentou-se desafios em forma de questões, explorando os conceitos de lógica, sequências, laços e condicionais estudados. Essas questões foram resolvidas de maneira plugada ou desplugada (em papel). Com essas questões permitiu-se observar aspectos de aprendizagem, sistematização do conhecimento e desenvolvimento cognitivo com intuito de verificar se o a plataforma CODE.ORG contribui para o apoio no processo de ensino a lógica de programação, identificando o índice de internalização e a fim de verificar se esse recurso tecnológico pode apoiar esse ensino.

Para realização das atividades do lightbot, as crianças foram divididas em pequenos grupos (separados por idade) e expostas a um determinado nível de problema do jogo. Dessa maneira, cada um dos grupos poderia expor a sua construção de pensamento para programar a sequência lógica que sendo executada faria com que o Robô percorra o caminho completo.

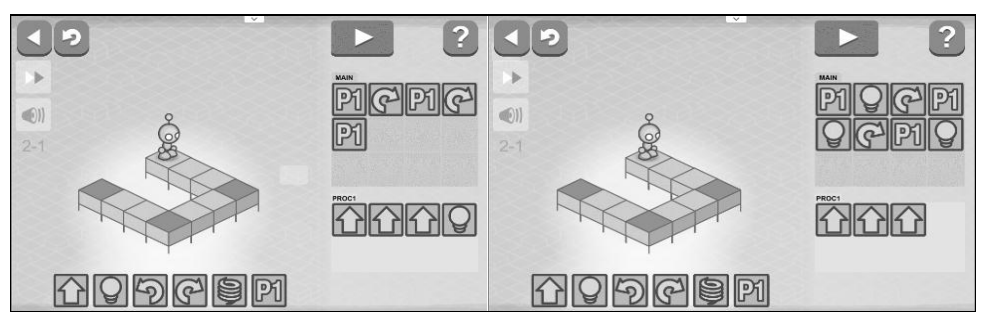

Figura 1. Duas soluções para o mesmo problema

Para os alunos participantes a experiência de programar o computador para realizar uma atividade foi instigante para a compreensão dos conhecimentos relacionados a lógica de programação, esses conhecimentos que muitas vezes são considerados de alta complexidade na computação, puderam ser compreendidos pelos alunos por meio do software. No decorrer das aulas, os alunos descreveram em forma de textos as vivências no laboratório, alguns destacaram que "é empolgante dá comandos ao computador e vê-lo realizar corretamente" outros afirmaram que com essa experiência desejam criar os seus próprios jogos e que gostariam de aprender como foram construídos os seus jogos preferidos. 
O Lightbot, com a sua estrutura de programação em ícones, atingiu aos nossos objetivos no início do estudo, despertando nos alunos o interesse por outros tipos de programação educativa como o Scratch, Kodu, dentre outros e incentivando a arte de pensar de forma mais estruturada. É importante citar que a maioria dos alunos levaram a experiência para suas casas, completando todas as fases do jogo, ganhando assim o certificado da CODE.ORG.

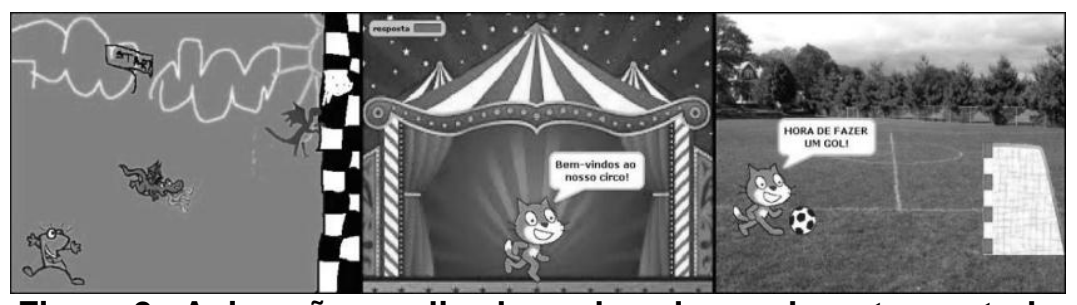

Figura 2. Animações realizadas pelos alunos durante o estudo

Para realização das atividades com o Scratch (demonstrado acima), os alunos realizaram estudos em relação à linguagem, aprendendo os seus conceitos básicos e suas categorias que são divididas em: movimento, aparência, som, caneta, controle, sensores, operadores e variáveis, cada uma delas é representada por uma cor, e seus blocos possuem funções diferentes, que auxilia ao aluno compreender de forma mais concreta o que utilizar em cada momento, facilitando também a leitura dos códigos criados.

Observou-se que nas primeiras experiências com o Scratch em que os alunos realizavam animações com os personagens e os objetos houve bastante facilidade de criação e gerando capacidade de compreensão mais abrangente da ferramenta, como por exemplo os recursos de biblioteca, sons, imagens, mudanças de palco. Durante todas as aulas os alunos tinham o interesse de avançar nos conhecimentos, estimulados por sua própria curiosidade buscavam utilizar blocos de funções mais avançados e dessa maneira conseguiam de forma individual criar programações livres a partir de sua criatividade.

A atividade com a linguagem Scratch e com os resultados apresentados durante o projeto final percebeu-se que os alunos aprenderam os conceitos iniciais da programação, agregando-se as suas atividades comuns. Verifica-se o entendimento do Pensamento Computacional com o desenvolvimento de forma concreta em uma linguagem visual.

\section{Considerações finais}

Esse trabalho apresentou como o Pensamento Computacional pode ser desenvolvido no cotidiano dos alunos, por meio do movimento dos códigos, trazendo um diferencial de ministrar conteúdos de forma lúdica, agregando os conceitos da Ciência da Computação para a Educação Básica. Os conceitos computacionais puderam ser identificados ao longo das etapas do trabalho.

Destaca-se como as atividades envolvendo a plataforma CODE.ORG se mostra como uma grande aliada na disseminação do ensino de computação desde o ensino básico, principalmente aplicado aos conceitos do Pensamento Computacional. Observase resultados significantes, que agregados ao ensino-aprendizagem possibilitam ao aluno ser estimulado a uma aprendizagem tecnológica construtiva, fornecendo resultados no seu processo de ensino como um todo. Espera-se incentivar iniciativas de ensino de programação nas escolas e encorajar discussões quanto ao ensino de conceitos de programação, como também contribuir com a disseminação dos jogos do 
VIII Congresso Brasileiro de Informática na Educação (CBIE 2019)

Anais do XXV Workshop de Informática na Escola (WIE 2019)

CODE.ORG para o ensino da programação e a avaliação dos efeitos da adoção de tais ferramentas para o ensino.

\section{Referências}

Code.org. Aprendendo a Ciência da Computação. Disponível em: < https://code.org/>. Acesso em: out. 2018.

Franca, R. S., Silva,W. C., and Amaral, C. J. H. Ensino de Ciência da Computação na Educação Básica: Experiências, Desafios e Possibilidades, 2014.

MCT. Ministério da Ciência e Tecnologia. Sociedade da Informação no Brasil. Livro Verde, Tadao Takahashi (org.). Brasília, 2000. Disponível em: <http://livroaberto.ibict.br/bitstream/1/434/1/Livro\%20Verde.pdf>. Acessoem: set. 2018.

Papert, S. Mindstorms: children, computers, and powerful ideas. Basic Books, Inc., New York, NY, USA, 1980.

SBC. Referenciais de Formação em Computação: Educação Básica, CSBC, Julho/2017. Disponível em: <http://www.sbc.org.br/files/ComputacaoEducacaoBasicaversaofinal-julho2017.pdf> Acesso em: fev, 2019.

Valente, José Armando. Computadores e Conhecimento: representando a educação. $2^{\text {a }}$ Ed., Campinas, SP: UNICAMP (NIED), 2018.

Vergara, Sylsia Constant. Projetos e relatórios de pesquisa em administração. 10. ed. São Paulo: Atlas, 2009.

Wing, J. Computational Thinking. Communications of the ACM, vol. 49, n. 3, p. 33, 2006. 